\title{
A CONCEPTUAL FRAMEWORK FOR TOTAL CONSTRAINT MANAGEMENT IN CONSTRUCTION
}

\author{
$\underline{\text { Ted Blackmon }}^{1}$, Rehul Saxena ${ }^{2}$, and Lingguang Song ${ }^{2} *$ \\ ${ }^{1}$ Construction Solutions, Bentley Systems, Houston, USA \\ ${ }^{2}$ Construction Management, University of Houston. Houston, USA \\ * Corresponding author (Isong5@uh.edu)
}

\begin{abstract}
Complex construction projects are subject to numerous constraints that limit the commencement or progression of field operations. Effective management of these constraints is a key element in the look-ahead planning process to ensure a constraint-free work plan, and thus efficient field operations. While past studiesprimarily deal with a limited set of constraint types, there is a need for a more thorough understanding and classification of common constraints across different industry sectors and work activity types, as well as a more practical way to identify and track constraints through a combination of automated and manual methods. This research proposes a Total Constraint Management (TCM) approach for construction constraint identification, tracking, and resolution. Within the TCM framework, a constraint classification method, incorporating trade-specific "constraint templates", facilitates constraint classification and identification for different types of construction work. To efficiently manage constraints in the field, this paper also discusses a process model for semi-automated and computerized constraint tracking and status reporting.The result of this study is valuable to the industry practitioners and software providers in developing better tools for constraint management and workfaceplanning.
\end{abstract}

Keywords: Constraints, Workface Planning, Total ConstraintManagement, Classification, Tracking

\section{INTRODUCTION}

Constraints can be defined as any condition, such as technical sequencing, temporal/spatial limitations, and safety/quality concerns, which prevent work plans assigned to construction crews from being successfully executed in the field.Complex construction projects, such as industrial plants, large infrastructure works (e.g., underground subways),and building facilities(e.g., hospitals, airports and campuses),are all subject to numerous constraints which invariably can have significant negative impact on overall project execution.

Beyond the more obvious topology constraints of material connectivity and interdependencies between various trades, other constraints should also be satisfied before work proceeds in the field. Examples of such constraints include access to the latest construction drawings and specifications (e.g., clearance of holds and responses to outstanding RFIs), availability of materials on-site, availability and assignment of labor resources, equipment, and tools, adequate space for work to be performed (e.g., the provisioning of temporary work platforms such as scaffolding), permits, quality control hold-points, safety checks, and more.

Unfortunately assignment of constraint free work to the field crews is not always the case. The sheer level of detail as well as the nature of the potential constraints forconstruction field work does not lend itself to be managedusing the project controls technique ofCritical Path Methodology (CPM), which continues to be the tool of choice for construction project management. Indeed 
higher-level construction plans as represented in a CPM schedule are highly useful for project management, and are appropriate for communicating overall plans and progress to key stakeholders, especially as a part of administering contracts; however they are not adequate for effective identification and tracking of detailed constraints in the field.

At a practical level, CPM scheduling applications with excessive details become difficult to maintain. Even more fundamentally, CPM considers only time and precedence constraints [1], and does not cover the full spectrum of constraint types encountered in the field. Furthermore, a CPM schedule can only be created following the development of a fixed plan, as the work break-down structurefor a project. Given the nature of construction as a wicked problem [2],it is ill advised to attempt to develop a fixed definitive plan of detailed activities at the level of material component sequencing. Rather it is better to allow flexibility in the definition of crew-level work package scope so as to retain increased agility in dealing with the uncertainly of the constraints.

Construction field activities are more appropriately managed through dynamic re-planningof crew-level work packages, given the large number of a-priori unknowns and constraints that exist. However, manual identification of constraints on crew-level work packages is an arduous task, most oftenaccomplished throughad-hoc methods enacted during the execution stage of construction work in the field. Without increased automation support, constraint management is generally brute force, left up to instinctive decision making by experienced field supervision.

Given this dilemma, it should not be a surprise that various studies around the world show that on average field crews only achieve about 40-60\% efficiency andsafety accidents can account for $3-6 \%$ of the total project costs[3]. When crews do not have necessary resources and information to conduct their work, time is wasted due to waiting for or gatheringresources,slowing down progress, or taking early breaks [4]. Moreover, when a schedule is compressed in order to recover schedule delay, crews may become rushed, possibly withmultiple trades stacked together. Without well-defined and executable work plans, unsafe operations and safety accidents more readily occur. This is clearly a planning problem, not a labor issue.

This paperproposes a structured approach, Total Constraint Management (TCM), integrating agile construction methods for look-ahead planning with a semi-automated process of constraint identification, tracking, and resolution. Trade-specific “constraint templates” facilitate constraint classification and identification against Field Installation Work Packs (FIWPs). Systematic management and tracking of FIWPs against constraints provide field crews with work plans at a detailed material component level, free of constraints.

Meanwhile, construction management personnel, operating at the level of a traditional CPM schedule, are provided with visibility into the available work buffers for field crews relative to the CPM schedule activities. Visibility windows may be extended out beyond 3 to 4 weeks in a traditional look-ahead schedule, to 8 weeks or more, with insight into work hours required to stay on schedule plotted against planned work hours that are free of constraints.

\section{RELATED STUDIES}

The importance of performing detailed planning and constraint analysis to issue executable work plans to the field has been widely recognized by the industry. Constraint analysis is a critical component in the Last Planner concept of Lean Construction developed by Ballard [5], as well as part of the WorkFacePlanning methodology more recently promoted by the Construction Owners Association of Alberta (COAA) [4], and currently a study topic of the Construction Industry Institute (CII). Past research efforts related to modeling of constraints have been primarily focused on understanding a limited set of constraint types, such as technological, resource, spatial, 
or information constraints [6]. Although these researches provided accurate methods in evaluating individual constraints, they fall short in thoroughly identifying and classifying the full suite of constraints realized in the field in real world projects.

These field production management concepts and research efforts certainly highlight the importance of constraint analysis and formalize this as a critical step in planning; however they do not specify details as to how constraints can be consistently identified and tracked in the field in a manner that is practical to achieve on a project.

Building upon the key concepts in lean construction, Choo et al. [7] describe a database application, "WorkPlan”, for assigning and tracking constraints against crew level work packages. Although certainly a major step in the right direction, the application described still requires constraints to be manually identified and tracked. Sriprasert and Dawood [8] outline requirements for a next generation suite of project control applications, and even developed a prototype system for constraint-based construction planning and control based upon combining the Last Planner and 4D concepts. However, it appears that limited progress was made beyond an academic prototype for its practical use in real world projects.

In summary, there is a need for a better understanding of constraints across different types of construction workas well as techniques to more efficiently addressconstraints for construction projects. Independent of the knowledge and research into this area, current constraint management practice in industry can be best described as informal, ad hoc, and heavily dependent on planner's experience and subjective judgment.

\section{TOTAL CONSTRAINT MANAGEMENT (TCM)}

It is proposed here that without increased automation, Total Constraint Management is difficult (albeit not impossible) to implement, particularly given the sheer number of constraints that must be identified and tracked on a large and complex construction project. Moreover, much of the information related to the constraints is often contained across a suite of disparate IT applications on a construction project, operating as islands of automation. Hence, it is further postulated that the WorkFace Planning process, incorporating constraint management at a component-level of detail, is a natural driver for effective data integration and aggregation across disparate IT systems utilized for construction. Fig. 1 graphically depicts the WorkFace Planning (WFP) process as a swim-lane diagram. WFP is the process of getting all elements ready to enable crews to perform quality work in a safe, effective and efficient manner [4]. It's about getting the right things to the right people at the right time to improve productivity.

A key concept of WFP is the Field Installation Work Package (FIWP), which can be defined as a construction deliverable broken down from a higher level construction deliverable, the Construction Work Package (CWP). Whereas the CWP operates at the level of construction management in alignment with the Work Breakdown Structure in the CPM schedule, the FIWP operates at the level of detailed look-ahead planning outside of the CPM schedule. Hence, Each CWP is decomposed into a series of smaller discipline-specific FIWPs, typically containing one to two weeks of work. FIWPs provide a meaningful level of detail for crew-level management to explicitly identify and track all required resources and information prior to work starting.At the heart of the WFP process is the process to identify and track constraints, as well as expedite constraints in order to enable FIWPs to be released to the field crews to reliably execute the work. To ensure comprehensive yet efficient management of constraints, a computerized system for TCM augments the WFP process by extending it with a structured and consistent approachin identifying, tracking, and resolving constraints. 


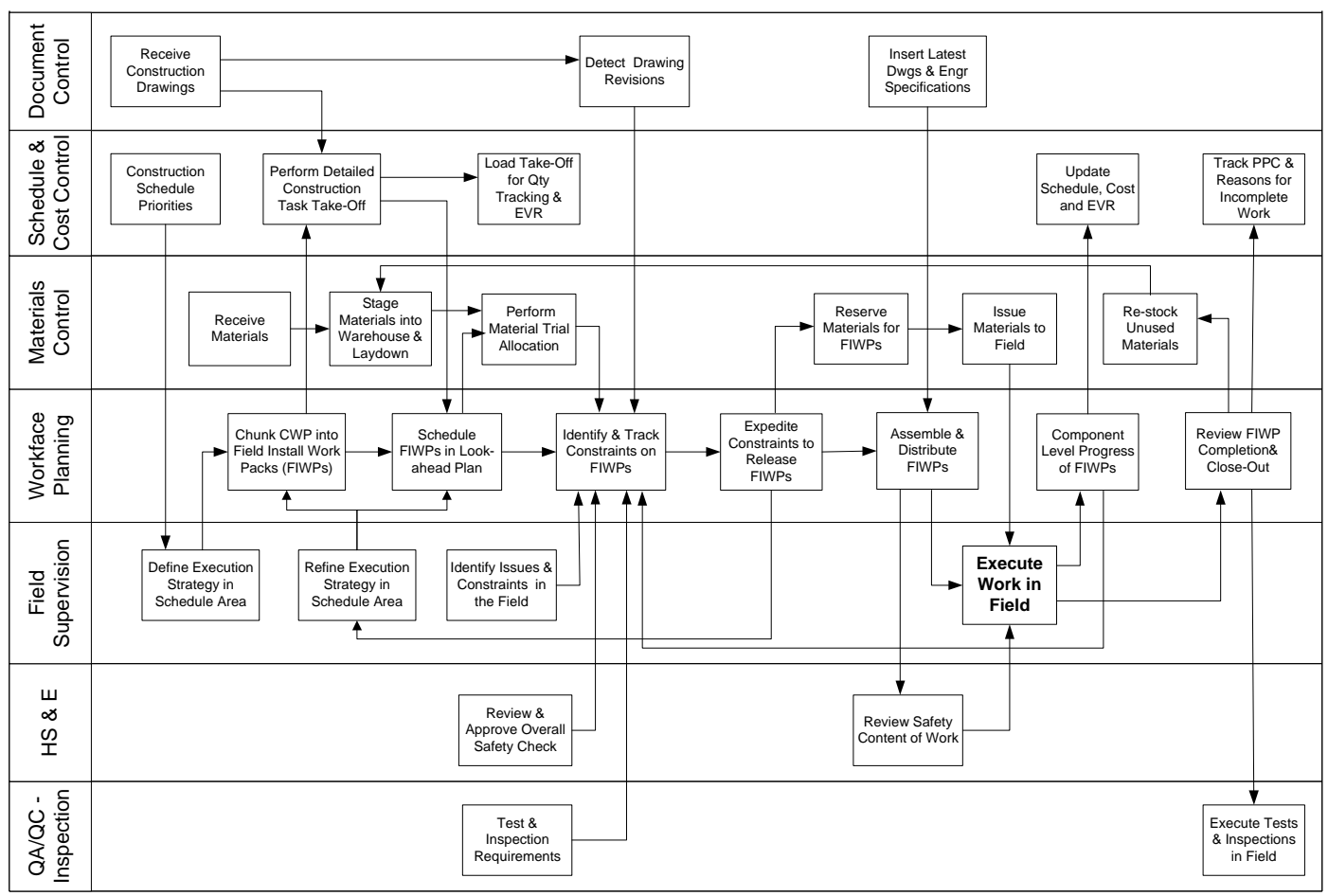

Figure 1 - Construction Industry Work Flow for WorkFace Planning

Fig. 2 graphically depicts the system for Total Constraint Management in construction.FIWPsare tracked from initial creation, through review and approval, assignment of target dates and resources, constraintmanagement prior to release to the field, assembly, sign-off, through execution and final close-out. After initial creation of FIWPs from a CWP, a FIWP must be planned first. This includes user-assigned target start and finish dates to the FIWP and these start/finish dates should be in alignment with the CPM construction schedule. Meanwhile, a crew will also be assigned to a FIWP.

\section{AUTOMATINGCONSTRAINT MANAGEMENT}

The next critical step in FIWP planning is to identify constraints specific to the work on hand. If constraints are not properly identified, subsequent conflicts in the field are likely to occur.Today's projects are becoming more technically complex and logistically challenging, which exposes construction operations to even more complex constraints. Therefore, constraint identification and classification through a structured approach is the very first step toward a “zero-constraint” environment. To achieve that, we propose a classification method combined with a template approach for constraint instantiation. This is further bolstered with an open-data integration approach with external IT systems to identify, track and update the status of constraints at a detailed component level. Although construction projects are unique, they share some similar types of constraints at the operational level and this observation motivated us to develop a classification scheme to organize the potentially large amount of constraints. Numerous constraints were identified through a literature search and they are grouped into three broad categories and a number of subcategories according to their characteristics, as shown in Table 1.Although some constraints are very unique to a particular type of work, they can typically be assigned to one of the abovementioned categories and subcategories for easier identification and tracking. For example, the water level for off-shore work can be assigned to the "Environmental conditions" subcategory. 


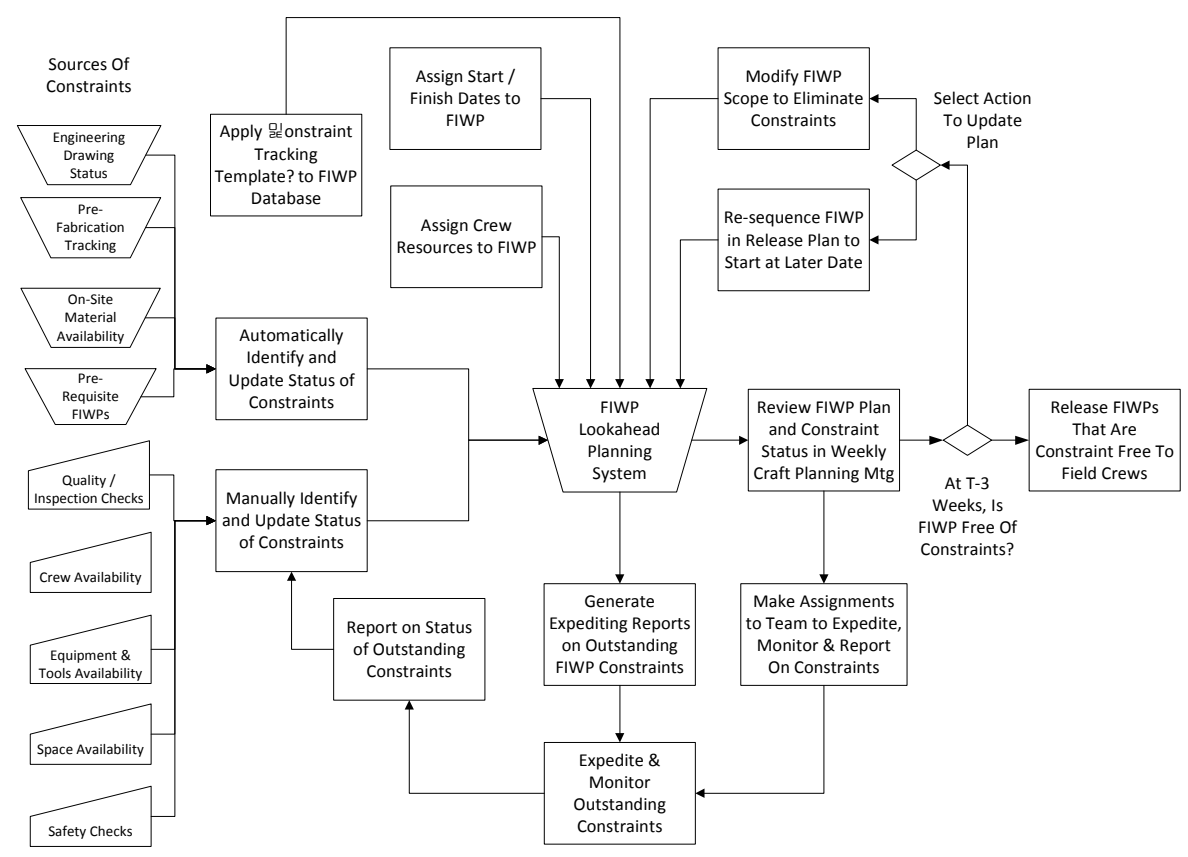

Figure 2 - System for Total Constraint Management of Field Installation Work Packs

Table 1. Constraint classification

\begin{tabular}{|l|l|}
\hline Category \& definition & Subcategories \\
\hline $\begin{array}{l}\text { Physical category: } \\
\text { Constraints related to any } \\
\text { physical properties of the site } \\
\text { and the work }\end{array}$ & $\begin{array}{l}\text { Pre-requisite work; storage } \\
\text { space; work space; safety \& } \\
\text { health; temporary structures; } \\
\text { site facilities/supplies; and } \\
\text { environmental conditions }\end{array}$ \\
\hline $\begin{array}{l}\text { Resources category: } \\
\text { Constraints on labor, material, } \\
\text { and equipment/tool resources }\end{array}$ & $\begin{array}{l}\text { Workforce; material; } \\
\text { equipment; tools; and } \\
\text { subcontractors }\end{array}$ \\
\hline $\begin{array}{l}\text { Information category: } \\
\text { Drawings, instructions, } \\
\text { permits, and plans that are } \\
\text { needed for performing work }\end{array}$ & $\begin{array}{l}\text { Scope definition; design } \\
\text { Information; administrative } \\
\text { information/permit; quality \& } \\
\text { inspection; and transportation } \\
\text { planning }\end{array}$ \\
\hline
\end{tabular}

Based on the categorization, pre-defined constraint templates can be automatically applied to a newly created FIWP. Templates are defined based upon a combination of discipline and activity type (e.g., pipe installation,steel erection, and pipe testing), and can be configured by the user.Once the template is applied to a FIWP, it instantiates a set of pre-defined constraints. The advantage of leveraging templates is that it improves consistency, completeness, and accuracy of constraint identification and minimizes the chance of overlooking certain constraints. Table 2 shows an example template for steelerection.
Table 2. Constraint template for steel erection

\begin{tabular}{|c|c|}
\hline Category & Sample \\
\hline \multicolumn{2}{|l|}{ PHYSICAL } \\
\hline Pre-requisite work & $\begin{array}{l}\text { Foundation ready for erection (e.g. anchor } \\
\text { bolts installed and checked) }\end{array}$ \\
\hline Storage space & $\begin{array}{l}\text { Adequate space/condition for structural } \\
\text { member storage }\end{array}$ \\
\hline Work space & Pre-assemble area identified and available \\
\hline Safety \& health & $\begin{array}{l}\text { Safety and hazard issues identified and } \\
\text { addressed; special PPE requirements } \\
\text { identified and available }\end{array}$ \\
\hline Temp. structures & Scaffold/man-lift requirements completed \\
\hline Facilities/supplies & Fabrication plants, etc. \\
\hline $\begin{array}{l}\text { Environmental } \\
\text { conditions }\end{array}$ & $\begin{array}{l}\text { Temp variation during the year, water level } \\
\text { etc. }\end{array}$ \\
\hline \multicolumn{2}{|l|}{ RESOURCES } \\
\hline Workforce & $\begin{array}{l}\text { Special training/certification requirements } \\
\text { identified and completed (e.g. safety and } \\
\text { equipment operation) }\end{array}$ \\
\hline Material & $\begin{array}{l}\text { Structural members available; field supply } \\
\text { materials available; warehoused materials } \\
\text { bagged and tagged }\end{array}$ \\
\hline Equipment & $\begin{array}{l}\text { Crane available and scheduled; required } \\
\text { rigging and accessories available }\end{array}$ \\
\hline Tools & Special tools identified and available \\
\hline Subcontractor & Vendors/subcontractors/surveyor scheduled \\
\hline \multicolumn{2}{|l|}{ INFORMATION } \\
\hline Scope definition & Erection items clearly identified \\
\hline Design Information & $\begin{array}{l}\text { All latest drawings and spec available; lift } \\
\text { plan completed; rigging plan completed, } \\
\text { reviewed, and authorized }\end{array}$ \\
\hline Admin. /permit & Work permits obtained \\
\hline $\begin{array}{l}\text { Quality \& } \\
\text { inspection }\end{array}$ & $\begin{array}{l}\text { Inspection and testing requirements listed } \\
\text { for performance and sign-off; 3rd party } \\
\text { inspection/testing scheduled }\end{array}$ \\
\hline $\begin{array}{l}\text { Transportation } \\
\text { planning }\end{array}$ & $\begin{array}{l}\text { Transportation for equipment and } \\
\text { structural members scheduled }\end{array}$ \\
\hline
\end{tabular}


To provide further automation, constraints types can be dividedinto two groups according to their sources. Some constraint types can be automatically identified and tracked based upon component status information in external data sources, whereas other constraints must be identified and tracked through manual input. This provides an opportunity to automate the tracking and updating of constraint status and make constraint management more efficient. Examples of such constraint types that could be automated include engineering drawing status, pre-fabrication status, on-site material availability, and the status of pre-requisite FIWPs. The other group of constraints involves those that are tracked manually, for example inspection and safety checks as well as crew and tool availability, which are typically gathered during weekly craft planning meetings.

Constraint classification and tracking makes constraint status reporting efficient. Outstanding constraints that must be removed before a FIWP can be released to the field can be reported by constraint category, responsible party, or level of urgency.FIWP plans and constraint status are reviewed in weekly craft planning meetings, where teams are assigned to expedite and monitor the status of outstanding constraints. Alternatively, expediting messages can be generated automatically by the database and sent to the responsible party for a resolution.

Once a FIWP is constraint-free, it can then be released to the field. Otherwise, two options can be considered. With approval obtained, the original FIWP can be modified to account for missing resources that make it constraint-free for release. If this is not feasible, a decision can be made to re-sequence the FIWP in the overall release plan and delay it to a later start date.

\section{CONCLUSIONS}

The Total Constraint Management (TCM) concept integrates workface planning with the process of semiautomated constraint identification, tracking, and resolution. A constraint categorization and work-specific template approach is used to facilitate consistent and complete constraint identification. In addition, a reference model for a computerized system is described to manage constraint status tracking, reporting, expediting, and monitoring.

\section{REFERENCES}

[1]Pultar, M., "Progress-based construction scheduling.” J. of Constr.Engrg.\&Manag., 116(4), pp. 670-688., 1990.

[2] Lane, R. and Woodman, G.,"Wicked problems, righteoussolutions - back to the future on large complex projects", Prod. 8th Annual Meeting of the International Group for Lean Construction, Brighton, UK., 2000.

[3] Banik, G. C., “Construction productivity improvement”, ASC Proceedings of the 35th Annual

Conference, San Luis Obispo, CA., 1999.

[4] Construction Owners Association of Alberta (COAA), http://www.coaa.ab.ca/Productivity/WorkFacePlanning, accessed March 15, 2011

[5] Ballard, G., "Last planner system of production control.” Ph.D. Dissertation. Univ. of Birmingham, Birmingham, UK., 2000.

[6] Chua, D. K. H., Shen, L. J., and Bok, S. H., "Constraint-based planning with integrated production scheduler over the Internet.” J. Constr. Engrg. and Mgmt., Vol. 129(3), pp. 293-301., 2003.

[7] Choo, H. J., Tommelein, I. D., Ballard, G., and Zabelle, T. R., "WorkPlan: constraint-baseddatabase for work package scheduling.” J. Constr. Engrg. and Mgmt., Vol. . 125(3), pp. 151-160.

[8] Sriprasert, E. and Dawood, N, "Requirements identification for 4D constraint-based construction planning and control system.” Proc. of CIB W78 conference, Aarhus, Danmark, 2002. 